\title{
Emissões de gases de efeito estufa e eficiência ambiental no Brasil
}

\author{
Greenhouse gases emissions and Brazilian environmental efficiency
}

\author{
Thiago Costa Soares ${ }^{(1)}$ \\ Dênis Antônio da Cunha (2) \\ (1) Universidade Federal de Juiz de Fora \\ (2) Universidade Federal de Viçosa
}

\begin{abstract}
This paper aims to analyze the environmental efficiency of Brazilian municipalities and to relate it to a set of local socioeconomic characteristics, controlling technological heterogeneity and spatial dependence. A Metafrontier Data Envelopment Analysis (DEA) method has been applied to measure the efficiency, based on the Brazilian greenhouse gas emissions. Afterward we estimate a Spatial Autoregressive model (SAR) relating environmental efficiency to municipal socioeconomic characteristics. The main results show that variables such as income and HDI were positively related to the environmental efficiency. On the other hand, inequality and education showed negative relations. In addition, we found evidence of "environmental spillover" effect, which could indicate positive externalities when sustainable practices are implanted at reginal level.
\end{abstract}

\section{Keywords}

greenhouse gas, environmental efficiency, Brazilian municipalities, data envelopment analysis, spatial autoregressive model.

JEL Codes C21, C61, O50.

\section{Resumo}

Este artigo tem como objetivo analisar a eficiência ambiental dos municípios brasileiros e relacioná-la a um conjunto de características socioeconômicas locais, controlando aspectos como heterogeneidade tecnológica e dependência espacial. Para tanto, utilizou-se o método de Análise Envoltória de Dados (DEA) Metafrontier para construir o indicador, que foi baseado nas emissões de gases de efeito estufa. Em seguida, ajustou-se um modelo que relaciona eficiência ambiental, características socioeconômicas e dependência espacial (Spatial Autoregressive Model). Os principais resultados revelaram que renda per capita e IDH se relacionaram positivamente com o indicador de eficiência. Por outro lado, as variáveis desigualdade e educação mostraram relação negativa com o indice. Ademais, houve evidências de efeito "spillover ambiental" entre municipios, indicando que a criação de práticas sustentáveis em âmbito local pode produzir externalidades positivas regionalmente.

\section{Palavras-chave}

gases de efeito estufa, eficiência ambiental, municípios brasileiros, análise envoltória de dados, modelo de regressão espacial.

Códigos JEL C21, C61, Q50. 


\section{Introdução}

As mudanças climáticas, bem como suas causas e consequências, representam um dos principais desafios que as diferentes sociedades ao redor do planeta enfrentam no século XXI (Martin; Maris; Simberloff, 2016). Esse fenômeno está diretamente associado às emissões antrópicas de gases de efeito estufa (GEE) (Intergovernmental Panel on Climate Change, IPCC, 2014). Por essa razão, cada vez mais países têm procurado aumentar a eficiência de suas atividades produtivas para garantir a redução de emissões (Zhang; Xing; Wang, 2016). O Brasil, que figura entre os dez maiores emissores mundiais de GEE (World Bank, 2016), tem assumido diversos compromissos voluntários de controle de suas emissões perante órgãos internacionais. Por meio de sua mais recente iniciativa, o país se comprometeu a reduzir as emissões de GEE em 43\% abaixo dos níveis de 2005 até 2030 (Intended Nationally Determined Contribution Towards Achieving the Objective of the United Nations Framework Convention on Climate Change, iNDC, BRASIL, 2015).

$\mathrm{O}$ atendimento de metas de redução de emissões, como as que o Brasil propõe, está diretamente ligado à melhoria da eficiência dos processos produtivos dos diferentes setores econômicos. Isso ocorre devido ao fato de que a produção de bens e serviços envolve, necessariamente, a geração de bens indesejáveis, como as emissões de GEE. Ademais, formuladores de política têm identificado que condições socioeconômicas e produtivas regionais desiguais têm causado incertezas e obstáculos ao êxito de políticas de mitigação (Zhang; Xing; Wang, 2016).

Nesse sentido, o presente estudo teve como objetivo analisar a eficiência ambiental brasileira, relacionando-a às emissões de GEE. Foi desenvolvida uma medida de eficiência ambiental em nível municipal, considerando a relação entre a produção de bens/serviços e emissões GEE. Procurou-se, ainda, analisar o efeito de variáveis exógenas sobre a performance ambiental regional, controlando aspectos como heterogeneidade tecnológica e spillovers ambientais.

A análise proposta neste artigo oferece importante contribuição à literatura em diferentes aspectos. Ao considerar as heterogeneidades municipais (área e condições edafoclimáticas, intensidade e especialização produtiva, consumo energético, problemas ambientais, pobreza etc.), pode-se oferecer direcionamento mais concreto para o atendimento das metas 
propostas pela iNDC nacional, ampliando as possibilidades de redução das emissões. Além disso, verificando o efeito das características regionais sobre os indicadores de eficiência, bem como a existência de relação espacial entre eles, são fornecidas informações sobre possíveis trajetórias que municípios brasileiros podem percorrer para produzirem de forma menos danosa ao meio ambiente. Isso poderia subsidiar a concessão de financiamentos baseados na eficiência das emissões, uma das propostas da política climática brasileira. Por fim, embora a análise desagregada da eficiência ambiental relacionada às emissões de GEE esteja consolidada na literatura internacional (Kortelainen, 2008; Li; Wang, 2014; Mei; Gan; Zhang, 2015; Zhang; Xing; Wang, 2016), o presente estudo é pioneiro ao considerar essa problemática em âmbito nacional.

Este estudo está organizado em outras quatro seções. A seção 2 aborda as questões teóricas que norteiam a análise sobre eficiência ambiental. Na seção 3 são descritos os procedimentos metodológicos realizados para criar e relacionar o indicador de eficiência ambiental às características socioeconômicas municipais. Na seção 4, os resultados são apresentados e discutidos. As principais conclusões e sugestões de política fecham o trabalho na seção 5 .

\section{A tecnologia do conjunto de possibilidades de pro- dução com produtos desejáveis e não desejáveis}

Modelos de eficiência ambiental têm sido sustentados pelo quadro teórico da fronteira de possibilidades de produção (FPP), visto que ele permite a inclusão de recursos naturais e da poluição (bem não desejável) na função de produção (Färe; Grosskopf; Tyteca, 1996; Chiu et al., 2012; Song; Hao; Zhu, 2015).

Formalmente, denotam-se bens desejáveis (produtos) por $y=\left(y_{1}, \ldots, y_{D}\right)$ $\in \mathfrak{R}^{D^{+}}$, bens não desejáveis (emissões de GEE, no presente estudo) por $b=\left(b_{1}, \ldots, b_{U}\right) \in \mathfrak{R}_{+}^{U_{+}}$e insumos (incluindo os naturais) por $x=\left(x_{1}, \ldots, x_{I}\right)$ $\in \mathfrak{R}^{I}$. Assume-se que esses conjuntos são limitados e fechados. Portanto, quantidades finitas de insumos produzem quantidades finitas de produtos e emissões. A tecnologia de produção pode ser definida por

$$
P(x)=\{(x, y, b): x \text { produz }(y, b)\}
$$


$O$ vetor de insumos $x$ produz os vetores $y$ e $b$ simultaneamente. Essa tecnologia é consistente com o modelo neoclássico tradicional, com exceção da especificação das emissões (Färe; Grosskopf; Noh, 2005). Supõe-se que as emissões de GEE são externalidades negativas da produção, isto é, bens que a sociedade não deseja. Assim, para qualquer nível positivo de produto, haverá emissão de poluentes. Para mitigar totalmente as emissões, a sociedade deve abrir mão da produção associada. Essa condição foi definida por Färe, Grosskopf e Lovell (1989) como weak disposability. Em notação,

$$
\text { se }(y, b) \in P(x) \text { e } 0 \leq \theta \leq 1 \text {, então }(\theta y, \theta b) \in P(x) \text {, }
$$

em que $\theta$ é o fator de abatimento de $b$. Zhang e Choi (2013) argumentam que a condição exposta em (2) significa que algum nível $b \neq 0$ é inevitável, uma vez que a única forma de mitigar totalmente as externalidades é deixando de produzir. Segundo Färe, Grosskopf e Lovell (1989), as propriedades (1) e (2) podem ser utilizadas para mensurar o esforço individual (de países, estados ou municípios) no controle das emissões (eficiência ambiental) através de dados observáveis.

Para concluir, pode-se afirmar que o desempenho ambiental dos municípios brasileiros pode ser mensurado por uma FPP que contenha produtos e emissões de GEE. A pressuposição de que os bens sejam produzidos conjuntamente permite analisar o desempenho municipal para produzir ao menor custo ambiental possível. Dessa forma, é possível criar medidas de desempenho que são compatíveis com o arcabouço teórico-analítico da economia neoclássica, adicionando as externalidades na função objetivo.

\section{Metodologia}

\subsection{Construção dos indicadores de eficiência ambiental}

No presente estudo, empregou-se o método de Análise Envoltória de Dados (Data Envelopment Anaysis, DEA) para construir a FPP com produção e emissões de GEE. Retomando a notação da seção anterior, consideram-se vetores de variáveis de produção $y=\left(y_{1}, \ldots, y_{D}\right) \in \mathfrak{R}^{D}$, emissões $b=\left(b_{1}, \ldots, b_{U}\right) \in \mathfrak{R}^{U}+$ e insumos $x=\left(x_{1}, \ldots, x_{I}\right) \in \mathfrak{R}^{I}$, de tal forma que toda unidade tomadora de decisão (municípios) $\left(n \in \mathfrak{R}^{N_{+}}\right.$) apresente uma estru- 
tura do tipo descrito em (1). As regiões eficientes ambientalmente (escores unitários) são aquelas que se encontram sobre a FPP, ao passo que o grau de ineficiência e o potencial de abatimento de GEE são mensurados pela distância geométrica da FPP.

$O$ DEA assume que as unidades analisadas pertencem a uma fronteira tecnológica comum. Entretanto, essa condição pode não se aplicar aos municípios brasileiros, pois características regionais podem influenciar a forma de produzir. Para ilustrar, dados do Instituto Brasileiro de Geografia e Estatística (IBGE, 2016) revelam que 23\% dos municípios brasileiros (geralmente de pequeno porte) empregam mais da metade dos trabalhadores no setor agrícola. Nas localidades com mais de 200 mil habitantes, esse percentual é quase nulo.

Este estudo considerou essas diferenças por meio da abordagem DEA Metafrontier, que busca analisar a eficiência ambiental em grupos de municípios mais homogêneos. $O$ procedimento pode ser resumido dessa forma (O'Donnell et al., 2008): constroem-se indicadores de eficiência considerando uma única fronteira, de modo que $T^{m}=\{(x, y, b): x$ produz $(y, b)\}$. Por conseguinte, são construídos $k$ grupos a partir de unidades com tecnologias homogêneas, tal que

$$
\begin{aligned}
& T^{k}=\{(x, y, b): x \text { produz }(y, b) \text { no grupo } k\} \text { e, } \\
& T^{m}=\left\{T^{1} \cup T^{2} \cup T^{3} \cup \ldots T^{k}\right\} .
\end{aligned}
$$

Dessas duas etapas, extraem-se informações sobre a eficiência da estrutura produtiva (tecnológica, meta-technology: $\mathrm{MME}$ ) e do controle de emissões (group technological efficiency: GTE). A primeira definição analisa todas as unidades e aponta as estruturas produtivas mais eficientes. A segunda formulação compara somente unidades que fazem parte do mesmo grupo tecnológico. No segundo caso, a ineficiência ambiental decorre da gestão municipal.

Formalmente, sejam $\mathrm{MME}=\theta^{m}$ e GTE $=\theta^{k}$, em que $0 \leq \theta^{m} \leq 1$ e $0 \leq \theta^{k} \leq 1$ são escores de eficiência técnica obtidos nas fronteiras MME e GTE, respectivamente. A razão MTR (meta technology ratio) = MEE/GTE fornece a noção do problema causado pela heterogeneidade amostral (quanto menor o indicador, maior a evidência do problema). A Figura 1 permite visualizar o que está sendo exposto. 
Figura 1 Metafronteira e fronteira dos grupos

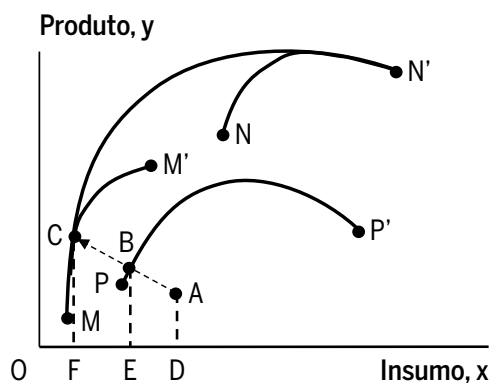

Fonte: Adaptado de Chiu et al., 2012.

A Figura 1 apresenta três tecnologias particulares, descritas pelas unidades M e M' (grupo 1), N e N' (grupo 2) e A, P e P' (grupo 3). As FPPs são as curvas que ligam os pontos $\mathrm{M}-\mathrm{M}^{\prime}, \mathrm{N}-\mathrm{N}^{\prime}$ e P-P', respectivamente. A linha M-N' que envolve as demais é a metafronteira. Para cada unidade, há um escore de eficiência associado à metafronteira (MME, eficiência da estrutura produtiva) e à fronteira local (GTE, eficiência da gestão). No caso de $\mathrm{A}$, esses indicadores são representados por $\operatorname{MEE}(\mathrm{A})=\mathrm{OF} / \mathrm{OD}$ e GTE $(\mathrm{A})=$ OE/OD. Portanto, descreve-se MTR (A) = OF/OE.

A ineficiência da estrutura (tecnológica) e do controle das emissões (gestão) são obtidas por TGI $(A)=\operatorname{GTE}(A)(1-\operatorname{MTR}(A))=$ FE/OD e GMI (A) $=(1-\operatorname{GTE}(\mathrm{A}))=\mathrm{ED} / \mathrm{OD}$ (Chiu et al., 2012). A ineficiência ambiental total é definida por MTI $(\mathrm{A})=\mathrm{TGI}(\mathrm{A})+\mathrm{GMI}(\mathrm{A})=\mathrm{FD} / \mathrm{OD}$.

Outra questão pertinente na análise são as diferentes possibilidades de retornos produtivos que os municípios podem assumir, mesmo em estruturas homogêneas. Normalmente, municípios de pequeno porte apresentam ganhos de escala mais que proporcionais aos recursos investidos - retornos crescentes de escala. Por outro lado, em municípios de porte maior estímulos nos recursos podem produzir impactos menores na produção em termos proporcionais - retornos decrescentes de escala. Há ainda situações em que a produção pode responder proporcionalmente ao aumento dos recursos - retornos constantes de escala.

Desse modo, buscou-se flexibilizar as FPPs a fim de permitir que os municípios possam apresentar "retornos variáveis de escala" (variable returnos to scale, VRS - Banker; Charnes; Cooper, 1984). Esse procedimento permite separar "eficiência de escala" e "eficiência técnica". O segundo tipo representa a eficiência municipal no controle das emissões. Os problemas 
de programação linear (PPL) podem ser expressos por (4) e (5):

$\max \theta^{m}$

$$
\begin{aligned}
& \text { s.a. } \sum_{k=1}^{K} \sum_{n=1}^{N_{k}} \lambda_{n}^{k} x_{i n}^{k} \leq x_{i o}^{k}, \\
& i=1,2, \ldots, I \text {, } \\
& \sum_{k=1}^{K} \sum_{n=1}^{N_{k}} \lambda_{n}^{k} y_{d n}^{k} \geq y_{d o}^{k}, \\
& d=1,2, \ldots, D, \\
& \sum_{k=1}^{K} \sum_{n=1}^{N_{k}} \lambda_{n}^{k}(1 / b)_{u n}^{k} \geq(1 / b)_{d o}^{k}, \\
& u=1,2, \ldots, U \text {, } \\
& \sum_{k=1}^{K} \sum_{n=1}^{N_{k}} \lambda_{n}^{k}=1, \\
& k=1,2, \ldots, K, \\
& \lambda_{n}^{k} \geq 0 \\
& n=1,2, \ldots, N_{k},
\end{aligned}
$$

$\max \theta^{k}$

$$
\begin{aligned}
& \text { s.a. } \sum_{k=1}^{K} \sum_{n=1}^{N_{k}} \mu_{n}^{k} x_{i n}^{k} \leq x_{i o}^{k}, \quad i=1,2, \ldots, I \text {, } \\
& \sum_{k=1}^{K} \sum_{n=1}^{N_{k}} \mu_{n}^{k} y_{d n}^{k} \geq y_{d o}^{k}, \quad d=1,2, \ldots, D, \\
& \sum_{k=1}^{K} \sum_{n=1}^{N_{k}} \mu_{n}^{k}(1 / b)_{u n}^{k} \geq(1 / b)_{d o}^{k}, \quad u=1,2, \ldots, U, \\
& \sum_{k=1}^{K} \sum_{n=1}^{N_{k}} \mu_{n}^{k}=1, \quad k=1,2, \ldots, K, \\
& \mu_{n}^{k} \geq 0, \quad n=1,2, \ldots, N_{k},
\end{aligned}
$$

em que $\lambda_{n}^{k}$ e $\mu_{n}^{k}$ são as variáveis de decisão dos modelos (4) e (5) que projetam o município para a FPP quando $\theta^{m}<1$ e $\theta^{k}<1$, respectivamente.

Para definir os $k$ grupos, a literatura consultada recomenda critérios proxies da tecnologia produtiva municipal, que podem ser geográficos, sociais, econômicos etc. (Chiu et al., 2012; Li; Wang, 2014; Mei; Gan; Zhang, 2015). No caso brasileiro, apenas critérios geográficos não são suficientes para definir fronteiras tecnológicas, pois existem diversos municípios com estruturas produtivas semelhantes que estão localizados em regiões diferentes. Esse argumento se estende à renda e outras variáveis. Dessa forma, primeiramente foi realizada uma divisão seguindo critérios populacionais, estabelecendo cinco agrupamentos (Tabela 1$)^{1}$.

1 Regra semelhante foi adotada por Rocha et al. (2012) em análise sobre a eficiência na gestão da saúde. 
Tabela 1 Classificação dos municípios por porte populacional

\begin{tabular}{lrrrr}
\hline Porte & Regra & Municípios (qt) & Percentual (\%) \\
\hline Pequeno I (PQI) & Até 20.000 & 3.244 & 67,76 \\
\hline Pequeno II (PQII) & 20.001 até 50.000 & 991 & 20,71 \\
\hline Médio (MD) & 50.001 até 100.000 & 309 & 06,45 \\
\hline Grande (GR) & 100.001 até 900.000 & 226 & 04,72 \\
\hline Metrópole (MT) & Mais de 900.000 & 17 & 00,36 \\
\hline Total & & 4.787 & 100,00 \\
\hline
\end{tabular}

A partir da subdivisão apresentada na Tabela 1, foram criados subgrupos em cada classe de tamanho com base em um conjunto de variáveis sugeridas por Iyer, Rambaldi e Tang (2006), Oh e Lee (2010), Chiu et al. (2012) e Zhang e Choi (2013) (Tabela 2). As variáveis utilizadas representam a especialização produtiva (através dos indicadores de escolaridade e participação dos setores na economia) e o desenvolvimento municipal (através dos indicadores de renda e desenvolvimento). Assim como em Chiu et al. (2012), foi utilizada a técnica cluster analysis. Adotaram-se os procedimentos $k$-médias e a distância Euclidiana padronizada, delimitando um máximo de quatro grupos.

\subsection{Relação entre eficiência ambiental e características regionais}

O indicador de eficiência ambiental demonstra a habilidade de um município para produzir minimizando a emissão de GEE. Portanto, conhecer a relação que características municipais e regionais têm com o indicador pode fornecer importantes informações para a formulação de políticas ambientais. $O$ procedimento consiste em estimar $\mathrm{o}$ indicador de eficiência ambiental descrito na seção anterior e utilizá-lo como variável dependente em um modelo econométrico no qual características municipais e regionais são variáveis explicativas:

$$
\theta^{k}{ }_{n}=\rho W \theta^{k}+\beta Z_{n}+\varepsilon_{n},
$$

em que $\theta^{k}{ }_{n}$ é a eficiência ambiental do $n$-ésimo município $(\mathrm{n}=1,2, \ldots, \mathrm{N})$, estimada pelo procedimento bootstrap de Simar e Wilson (1998) ${ }^{2} ; \rho W \theta^{k}{ }_{n}$ 2 O procedimento bootstrap torna a variável "eficiência" um processo gerado por dados aleatórios, suposição necessária para a construção de modelos econométricos. Além disso, esse 
denota a defasagem espacial da eficiência ambiental; o termo $W$ é uma matriz de pesos espaciais que captura a dependência espacial da variável dependente (neste estudo, adota-se a matriz do tipo "rainha" ${ }^{3}$ ); e $\rho$ é um parâmetro a ser estimado que fornece a direção da relação. Admitindo a existência de transbordamentos, espera-se $\rho>0$. Utiliza-se o coeficiente $I$ de Moran para calcular a autocorrelação espacial entre as localidades (Anselin, 1988). $\beta$ é o vetor $(Z \times 1)$ de parâmetros a serem estimados, os quais fornecem os efeitos marginais das variáveis explicativas; $Z_{n}$ é a matriz $(N \times Z)$ de variáveis explicativas com informações sobre as características municipais; e $\varepsilon_{n}$ é um distúrbio estocástico, $\varepsilon_{n} \sim$ iid $\left(0, \sigma^{2}\right)$. Os escores de eficiência estão restritos a um intervalo $(0,1)$. Portanto, assumindo que todos os municípios produzem quantidades positivas de bens desejáveis e não desejáveis (poluentes), a eficiência relativa será, no máximo, igual à unidade (situação na qual o município é ambientalmente eficiente).

O modelo descrito na expressão (6) é denominado Spatial Autoregressive (SAR). O SAR mostra a existência de transbordamentos ambientais quando a variável dependente do município $i$ afeta a variável dependente do município $j$ (e vice-versa). ${ }^{4}$ A inclusão do termo "espacial" se justifica em razão da importância da difusão tecnológica no contexto ambiental (Beise; Rennings, 2005; Ashworth; Geys; Heyndels, 2006; Huber, 2008).

\subsection{Dados e variáveis utilizados}

A construção da base de dados baseou-se na disponibilidade comum das informações sobre os municípios brasileiros em 2010 (estrutura cross-section). A escolha das variáveis, por sua vez, teve como suporte a literatura especializada internacional, a exemplo dos trabalhos de Chung, Färe e Grosskopf (1997), Färe, Grosskopf e Lovell (1989), Färe e Primont (1995),

procedimento reduz substancialmente os problemas de sensibilidade dos escores de eficiência (Simar; Wilson, 1998).

3 A matriz rainha considera vizinhos aqueles municípios que partilham fronteiras geográficas físicas e os vértices do mapa. Para LeSage (1999), essa estrutura é uma das mais indicadas por ampliar a definição de vizinhos geográficos. Além disso, após testes preliminares (procedimento de Baumont et al., 2004), constatou-se que essa estrutura capturou melhor a correlação espacial nos dados.

4 A especificação do SAR indica um possível problema de endogeneidade, pois a dependência espacial ocorre de forma multidirecional (processo de causação circular). Para corrigir esse problema, estima-se o modelo por máxima verossimilhança (MV). 
Färe e Grosskopt (2004), Färe, Grosskopt e Noh (2005), Kuosmanen e Kortelainen (2005), Afonso, Schuknecht e Tanzi (2006), Kortelainen (2008), Zhou e Ang (2008), Zhou, Han e Ang (2010), Oh e Lee (2010), Chiu et al. (2012), Wang, Zhang e Zhang (2013) e Zhang e Choi (2013).

As emissões de GEE foram representadas por um indicador em toneladas equivalentes de $\mathrm{CO} 2$, a partir do potencial de aquecimento global (PAG) dos gases $\mathrm{N} 2 \mathrm{O}$ (PAG de 310), CH4 (PAG de 21) e CO2 (PAG igual a 1) (Brasil, 2013), que são os principais GEE, segundo o IPCC (2014). Os dados foram extraídos da base Emissions Database for Global Atmospheric Research (EDGAR, FT V4.2 2010), desenvolvida pela European Commission (Joint Research Centre, JRS) e Netherlands Environmental Assessment Agency (PBL).

Os dados são calculados separadamente para cada gás e país, por meio de informações econômicas por setor (agricultura, indústria e serviços, para diferentes tipos de atividades setoriais, como manejo, transporte, queima de combustíveis fósseis e outras). Adota-se uma combinação de tecnologias específicas de cada país, setor e gás, com fatores de emissão que dependem dos níveis tecnológicos (Gütschow et al., 2016).

A EDGAR disponibiliza observações georreferenciadas em um grid de 0,1 (cerca de 123,5 $\mathrm{km}^{2}$ ). As médias das emissões municipais para cada gás foram obtidas através da união dos pontos do grip e das coordenadas de latitude e longitude das fronteiras municipais e agrupadas em toneladas equivalentes de $\mathrm{CO} 2$ por quilômetro quadrado por ano (ton $/ \mathrm{km}^{2} / \mathrm{ano}$ ).

Há algumas limitações na base EDGAR. Primeiro, utilizam-se outras bases de dados extraídas de fontes primárias, medições próprias e projeções, podendo ter, portanto, algum grau de imprecisão. Porém, o próprio IPCC adota essas informações na construção de cenários de mudanças climáticas por serem uma das mais abrangentes atualmente. Além disso, a desagregação da base pode induzir erros na medição das emissões em 649 municípios com dimensões inferiores a 123,5 $\mathrm{km}^{2}$ (tamanho do grid) (11,7\% do total em 2010). Para reduzir esses problemas, excluíram-se os referidos municípios. Assim, considerou-se uma amostra de 4.787 localidades em 2010. ${ }^{5}$

A produção foi representada pelo Produto Interno Bruto Municipal (PIB-M) - valor adicionado, em termos monetários, de todos os setores da economia. Esses dados foram extraídos do IBGE (2016). 
Para representar o capital, utilizou-se a frota de veículos automotores produtivos, como caminhões, caminhões-tratores, tratores de roda e caminhonetes. Uma variável semelhante foi utilizada como capital por Speight e Thompson (2006) em uma análise sobre investimentos e também por der Eng (2008), como forma de estimar o estoque de capital na Indonésia. Essa variável foi retirada do Departamento Nacional de Trânsito (Denatran, 2015).

Com referência à variável trabalho, adotou-se a população economicamente ativa de 18 anos ou mais (PEA). A PEA representa o potencial de mão de obra do município. Os dados foram extraídos do Programa das Nações Unidas para o Desenvolvimento (PNUD, 2016).

Para representar o uso dos recursos naturais, Zhou et al. (2010) e Chiu et al. (2012) propõem incorporar o consumo de energia como insumo na função de produção. Não obstante, no Brasil, essa variável não está disponível em nível municipal. Para representá-la, optou-se por utilizar o número de domicílios com energia elétrica. Os dados foram extraídos do Portal Brasileiro de Dados Abertos (PBDA, 2016).

Na segunda etapa, as dimensões discutidas foram desigualdade, renda, desenvolvimento, especialização produtiva, educação e pobreza - dados extraídos do PNUD (2016). Além dessas, para retratar as políticas ambientais promovidas pelos municípios, foram inseridas dummies que indicam a presença (quando a dummy assume valor igual a 1) ou a ausência de determinadas ações em prol do meio ambiente - essas informações foram obtidas no PBDA (2016).

Sobre a desigualdade, Boyce (1994) e Gassebner, Lamla e Sturm (2006) argumentam que a concentração de renda impulsiona o uso dos recursos naturais e as emissões, em razão da baixa disposição a pagar pela preservação ambiental e da dominância de minorias de maior poder econômico, que tendem a barrar o surgimento de leis ambientais. Por esses motivos, espera-se que a desigualdade se associe negativamente com a eficiência ambiental.

Por outro lado, municípios com renda e níveis de desenvolvimento mais elevados tendem não somente a se especializar em atividades menos intensivas em emissões (em serviços, por exemplo), como também a se preocupar mais com as questões ambientais (maior disposição a pagar pela preservação). Inclusive, esse é um dos argumentos utilizados pelos pesquisadores que defendem a "curva ambiental de Kuznets (CAK)". ${ }^{6}$ Nesse sentido, são esperados reflexos positivos dessas variáveis sobre a eficiência ambiental. 
Outra importante questão diz respeito à especialização produtiva. Por construção, o DEA Metafrontier compara unidades que pertencem à mesma função de produção. Na prática, isso permite que determinada região possa ser eficiente, mesmo desenvolvendo atividades mais intensivas em emissões. Nessa perspectiva, o aumento da participação relativa de algum setor pode se associar positivamente com a eficiência ambiental, pois a especialização, naturalmente, melhora o uso dos recursos disponíveis.

Em algumas situações, no entanto, a direção da relação pode variar, como no caso da educação. Daren (2007) verifica que a escolaridade pode melhorar a produtividade e aumentar as emissões associadas. Já sob a perspectiva da CAK, o nível educacional poderia se correlacionar positivamente com a consciência ambiental (Stern; Common; Barbier, 1996). Por isso, a relação entre educação e eficiência ambiental pode ser positiva (prevalência do efeito conscientização), negativa (prevalência do efeito produtividade) ou até inexistente (caso em que os efeitos se anulam).

Esse também é o caso da pobreza. Conforme argumenta Yusuf (2004), não há consenso a respeito do efeito dessa variável sobre as emissões. Por um lado, a demanda pela redução da pobreza pode intensificar o uso dos recursos naturais e as emissões de poluentes. Por outro lado, a incidência dessa variável pode indicar a concentração de atividades de menor impacto ambiental, como agricultura para autoconsumo e pequenas atividades extrativistas.

Do ponto de vista da criação de políticas ambientais, espera-se que ações que promovam a conscientização ambiental e, ou, a existência de mecanismos que incentivem a conservação, possam estar associadas à redução das emissões. Para capturar esse possível efeito, incluíram-se dummies na modelagem.

Tabela 2 Descrição das variáveis e fontes dos dados

\begin{tabular}{llrrrr}
\hline Variáveis da primeira etapa (DEA) & Proxy & Sigla & Unidade & Fonte \\
\hline Variável & Produto Interno Bruto Municipal & PIBM & R\$ & IBGE \\
\hline Produto & Emissões de GEE & GEE & tCO2eq & EDGAR FTV4.2 \\
\hline Emissão de poluentes & Frota de veículos produtivos & CAP & Unidade & DENATRAN \\
\hline Capital & População Economicamente Ativa & PEA & Unidade & PNUD \\
\hline Trabalho & Número de domicílios com & ENE & Unidade & PBDA \\
\hline Recursos naturais & energia elétrica & & & & \\
\hline
\end{tabular}

(continua) 
Tabela 2 (continuação)

\begin{tabular}{|c|c|c|c|c|}
\hline \multicolumn{5}{|l|}{ Variáveis da segunda etapa (SAR) } \\
\hline Variável & Proxy & Sigla & Unidade & Fonte \\
\hline Pobreza & Percentual de pessoas pobres & POB & $\%$ & PNUD \\
\hline Participação da indústria & $\begin{array}{l}\text { Percentual dos ocupados } \\
\text { no setor industrial }\end{array}$ & IND & $\%$ & PNUD \\
\hline Participação da agropecuária & $\begin{array}{l}\text { Percentual dos ocupados } \\
\text { no setor agropecuário }\end{array}$ & AGR & $\%$ & PNUD \\
\hline Participação da extração & $\begin{array}{l}\text { Percentual dos ocupados } \\
\text { na extração mineral }\end{array}$ & MIN & $\%$ & PNUD \\
\hline Desigualdade de renda & Índice de Gini & GINI & Índice & PNUD \\
\hline Escolaridade & $\begin{array}{l}\text { Percentual dos ocupados } \\
\text { com ensino superior }\end{array}$ & EDU & $\%$ & PNUD \\
\hline Renda & Renda média dos ocupados & REN & $\mathrm{R} \$ / 0$ cupados & PNUD \\
\hline Índice de desenvolvimento & IDH-M & IDH & Índice & PNUD \\
\hline Coleta de lixo & $\begin{array}{l}\text { Percentual da população que } \\
\text { possui coleta de lixo }\end{array}$ & LIXO & $\%$ & PNUD \\
\hline Consumo sustentável & Iniciativas de consumo sustentável & CONS & Dummy & PBDA \\
\hline Conservação ambiental & $\begin{array}{l}\text { Ações para reduzir o consumo } \\
\text { de água e energia }\end{array}$ & ARAE & Dummy & PBDA \\
\hline Compromisso ambiental & Critérios ambientais para licitação & CALI & Dummy & PBDA \\
\hline Características regionais & Dummies regionais & REG & Dummy & IBGE \\
\hline \multicolumn{5}{|c|}{ Variáveis para a construção de Clusters municipais } \\
\hline Variável & Proxy & Sigla & Unidade & Fonte \\
\hline Educação & $\begin{array}{l}\text { Percentual dos ocupados } \\
\text { com ensino superior }\end{array}$ & EDU & $\%$ & PNUD \\
\hline Importância da agropecuária & $\begin{array}{l}\text { Participação da agropecuária } \\
\text { na produção total }\end{array}$ & AGRO & $\%$ & IBGE \\
\hline Importância da extração mineral & $\begin{array}{l}\text { Participação da extração mineral } \\
\text { na produção total }\end{array}$ & EXT & $\%$ & IBGE \\
\hline Importância da indústria & $\begin{array}{l}\text { Participação da indústria } \\
\text { na produção total }\end{array}$ & IND & $\%$ & IBGE \\
\hline Importância dos serviços & $\begin{array}{l}\text { Participação dos serviços } \\
\text { na produção total }\end{array}$ & SERV & $\%$ & IBGE \\
\hline Renda & Rendimento médio dos ocupados & REND & $\mathrm{R} \$ / 0$ cupados & PNAD \\
\hline Desenvolvimento humano & Índice de Desenvolvimento Humano & IDH & Índice & PNAD \\
\hline
\end{tabular}

No intuito de resumir melhor as variáveis e suas fontes, a Tabela 2 apresenta uma breve descrição por etapas da pesquisa. 


\section{Resultados e discussões}

Inicialmente, os municípios brasileiros foram organizados em cinco grandes grupos, com base no critério populacional, e classificados como: metrópoles, municípios de grande, médio e pequeno portes (categorias I e II). Dentro das faixas previamente definidas, reconfigurou-se a amostra em 19 grupos por meio da técnica de cluster analysis (descrição mais detalhada de cada grupo encontra-se na Tabela A1 do Anexo). Após esse processo, obtiveram-se os indicadores de eficiência ambiental por meio da comparação técnica entre municípios com características populacionais e produtivas semelhantes. Esses indicadores, por sua vez, foram utilizados como variável dependente na modelagem da eficiência (modelo SAR).

Dito isso, apresentam-se a seguir os principais resultados obtidos. Constatou-se que a eficiência ambiental dos municípios foi baixa na metafronteira $(0,222)$, a qual desconsidera a existência de heterogeneidade entre as observações. Estimando o desempenho dentro dos grupos, os escores médios subiram para 0,315. Em termos metodológicos, é importante destacar esse resultado como avanço deste estudo, porque diversas aplicações do método na área ambiental utilizam unidades com características distintas na mesma função de produção, como visto em Honma (2012) e Halko e Tzeremes (2013). Tendo em vista a magnitude da diferença dos escores médios, pode-se dizer que essa estratégia não é adequada, pois tende a transmitir conclusões equivocadas sobre a eficiência ambiental.

Nas Tabelas 3 e 4 são apresentados os resultados sobre o desempenho ambiental por grupos e os indicadores de eficiência por faixas, respectivamente.

Os resultados da Tabela 3 mostram que as metrópoles brasileiras são relativamente mais eficientes do que os municípios de grande, médio e pequeno portes. Para elucidar, observa-se a coluna "EFC': enquanto a eficiência está acima de $80 \%^{7}$ nesse grupo, seu valor não passa, em média, de $31 \%$ nos municípios de pequeno porte (II). Para entender melhor esse resultado, é necessário verificar com mais detalhes certas características dos agrupamentos.

No grupo das metrópoles, percebeu-se que os dados utilizados na fronteira de produção são bastante próximos entre si, em termos relativos. Por 7 As apresentações do indicador em termos percentuais são obtidas pela multiplicação do escore por 100 . 
exemplo, comparando especificamente Fortaleza (CE, eficiência de 73\%) e Salvador (BA, eficiência de 99\%), constatou-se que no primeiro a renda, o número de veículos e as emissões, todas por habitante, foram de $\mathrm{R} \$ 15$ mil, 0,03 veículos e 1,3 toneladas, respectivamente. No segundo, essas variáveis apresentaram valores de $\mathrm{R} \$ 13,7$ mil, 0,02 veículos e 1,2 toneladas, respectivamente.

Por outro lado, há bastante dispersão nos demais grupos. Escolhendo como referência o grupo de municípios pequenos (categoria II), verificou-se que Ituberá (BA, eficiência de 91\%) apresentou dados relativamente destoantes de Alta Floresta (MT, eficiência de 11\%). Em Ituberá, as variáveis renda, emissões e quantidade de veículos produtivos, per capita, foram cerca de $\mathrm{R} \$ 6$ mil, 1,3 toneladas e 0,02 veículos, respectivamente. Já em Alta Floresta, essas variáveis apresentaram valores de R \$ 14 mil, 28 toneladas e 0,10 veículos, nessa ordem.

Desse modo, ao comparar regiões dentro do seu respectivo grupo, é natural que a eficiência relativa seja maior, em média, nas classes relativamente mais semelhantes. A ideia exposta aqui é simples: como as metrópoles produzem (e emitem) de modo similar, não há grandes oportunidades para melhorar sua eficiência tendo como correspondência outras metrópoles. Não está sendo afirmado aqui que esse resultado indica que essas regiões não possam reduzir suas emissões. Pelo contrário, reforça-se o argumento de que, para melhorar sua qualidade ambiental, essas localidades devem encontrar soluções que vão além das práticas adotadas. Uma alternativa, em linha com a iNDC brasileira, seria desenvolver melhorias na infraestrutura de transportes, incentivando e melhorando a eficiência do transporte público em áreas urbanas. Em contrapartida, municípios menores podem reduzir suas emissões observando localidades com melhor desempenho ambiental. Por exemplo, há muitos municípios de pequeno porte com vocação agrícola (especialmente no Nordeste) com grandes áreas cultivadas utilizando sistemas agroflorestais que poderiam ser "imitados" por vizinhos menos eficientes. Admite-se, contudo, que essa alternativa pode esbarrar em diversos fatores, como na limitação produtiva do município, na resistência social, na disponibilidade de recursos naturais etc. Portanto, esses resultados devem ser interpretados com ponderação e analisados caso a caso. 
Tabela 3 Indicadores de eficiência ambiental por grupos, em 2010

\begin{tabular}{|c|c|c|c|c|c|c|c|c|}
\hline \multicolumn{9}{|c|}{ Metrópoles (17 observações) } \\
\hline Grupo & Características & GTE & MEE & MTR & TGI & GMI & MTI & EFC \\
\hline MT1 & Escolaridade e desenvolvimento médios & 0,999 & 0,724 & 0,725 & 0,274 & 0,001 & 0,275 & 0,998 \\
\hline MT2 & Industriais e desenvolvimento alto & 0,965 & 0,685 & 0,709 & 0,280 & 0,034 & 0,315 & 0,926 \\
\hline MT3 & Industriais e desenvolvimento médio & 0,941 & 0,744 & 0,775 & 0,196 & 0,059 & 0,256 & 0,871 \\
\hline MT4 & Escolaridade e desenvolvimento altos & 0,914 & 0,756 & 0,820 & 0,157 & 0,085 & 0,243 & 0,811 \\
\hline \multicolumn{9}{|c|}{ Grandes (226 observações) } \\
\hline Grupo & Características & GTE & MEE & MTR & TGI & GMI & MTI & EFC \\
\hline GR1 & Comerciais e desenvolvimento médio & 0,441 & 0,376 & 0,860 & 0,064 & 0,558 & 0,623 & 0,354 \\
\hline GR2 & Industriais e desenvolvimento médio & 0,570 & 0,418 & 0,743 & 0,152 & 0,429 & 0,581 & 0,462 \\
\hline GR3 & Agrícolas e desenvolvimento baixo & 0,411 & 0,360 & 0,878 & 0,050 & 0,588 & 0,639 & 0,311 \\
\hline \multicolumn{9}{|c|}{ Médios (309 observações) } \\
\hline Grupo & Características & GTE & MEE & MTR & TGI & GMI & MTI & EFC \\
\hline MD1 & Comerciais e desenvolvimento baixo & 0,388 & 0,323 & 0,855 & 0,064 & 0,611 & 0,676 & 0,313 \\
\hline MD2 & Agrícolas e desenvolvimento baixo & 0,621 & 0,342 & 0,515 & 0,279 & 0,378 & 0,657 & 0,529 \\
\hline MD3 & Industriais e desenvolvimento médio & 0,468 & 0,383 & 0,851 & 0,084 & 0,531 & 0,616 & 0,370 \\
\hline MD4 & Extrativistas e desenvolvimento médio & 0,708 & 0,424 & 0,571 & 0,284 & 0,291 & 0,575 & 0,518 \\
\hline \multicolumn{9}{|c|}{ Pequenos II (991 observações) } \\
\hline Grupo & Características & GTE & MEE & MTR & TGI & GMI & MTI & EFC \\
\hline PQII-1 & Agrícolas e desenvolvimento baixo & 0,409 & 0,229 & 0,526 & 0,180 & 0,590 & 0,770 & 0,354 \\
\hline PQII-2 & Extrativistas e desenvolvimento médio & 0,377 & 0,186 & 0,501 & 0,190 & 0,622 & 0,813 & 0,277 \\
\hline PQII-3 & Junção e desenvolvimento baixo & 0,256 & 0,211 & 0,883 & 0,045 & 0,743 & 0,788 & 0,194 \\
\hline PQII-4 & Industriais e desenvolvimento médio & 0,295 & 0,213 & 0,724 & 0,081 & 0,704 & 0,786 & 0,238 \\
\hline \multicolumn{9}{|c|}{ Pequenos I (3244 observações) } \\
\hline Grupo & Características & GTE & MEE & MTR & TGI & GMI & MTI & EFC \\
\hline PQI-1 & Junção e desenvolvimento médio & 0,229 & 0,190 & 0,839 & 0,039 & 0,770 & 0,809 & 0,189 \\
\hline $\mathrm{PQI}-2$ & Agrícolas e desenvolvimento baixo & 0,363 & 0,192 & 0,523 & 0,170 & 0,636 & 0,807 & 0,307 \\
\hline $\mathrm{PQI}-3$ & Agrícolas e desenvolvimento baixo II & 0,236 & 0,201 & 0,864 & 0,035 & 0,763 & 0,798 & 0,199 \\
\hline $\mathrm{PQI}-4$ & Industriais e desenvolvimento médio & 0,320 & 0,213 & 0,683 & 0,107 & 0,679 & 0,786 & 0,271 \\
\hline
\end{tabular}

Fonte: Resultados da pesquisa.

Nota: GTE = Eficiência ambiental estimada dentro do grupo; MEE = Eficiência ambiental estimada na meta-fronteira; MTR = Taxa meta-tecnologia; TGI = Ineficiência ambiental causada pelo gap tecnológico; GMI = Ineficiência ambiental causada pelo mau gerenciamento; $M T I$ = Ineficiência ambiental total; e EFC = Eficiência ambiental bootstrapping intra grupo .

Outro resultado que chama a atenção é a alta ineficiência causada pelo controle inadequado das emissões, sobretudo nos municípios de menor 
porte. Individualmente, o indicador GMI (que indica a ineficiência gerencial) foi superior ao TGI (que indica a ineficiência tecnológica ou estrutural) em mais de $95 \%$ das localidades. O problema de ineficiência gerencial ocorre quando uma região não adota boas práticas produtivas devido ao gerenciamento inadequado. Pode-se citar como exemplo a questão dos aterros sanitários: grande parte dos municípios brasileiros ainda não trata adequadamente seus resíduos, mesmo havendo legislação sobre o tema. Com efeito, esses municípios emitem quantidade de poluentes que poderia ser evitada, caracterizando claramente um problema de gestão.

Tabela 4 Indicadores de (in)eficiência ambiental, por faixas

\begin{tabular}{|c|c|c|c|c|c|c|c|c|c|c|}
\hline \multirow{2}{*}{ Faixas } & \multicolumn{2}{|r|}{ MEE } & \multicolumn{2}{|r|}{ GTE } & \multicolumn{2}{|r|}{ TGI } & \multicolumn{2}{|r|}{ GMI } & \multicolumn{2}{|r|}{ MTI } \\
\hline & $\mathbf{N}^{0}$ & $\%$ & \begin{tabular}{l|}
$\mathbf{N}^{0}$ \\
\end{tabular} & $\%$ & $\mathbf{N}^{0}$ & $\%$ & $\mathbf{N}^{0}$ & $\%$ & $\mathbf{N}^{0}$ & $\%$ \\
\hline $0,750-1,000$ & 107 & 2,14 & 264 & 5,52 & 9 & 0,10 & 2326 & 48,59 & 3516 & 73,45 \\
\hline $0,500-0,749$ & 182 & 3,80 & 436 & 9,12 & 51 & 1,07 & 1765 & 36,87 & 983 & 20,54 \\
\hline $0,25-0,499$ & 987 & 20,62 & 1775 & 37,08 & 301 & 6,29 & 432 & 9,02 & 182 & 3,80 \\
\hline $0,01-0,249$ & 3511 & 73,34 & 2312 & 48,38 & 4426 & 92,46 & 264 & 5,52 & 106 & 2,21 \\
\hline
\end{tabular}

Fonte: Resultados da pesquisa.

Nota: MEE = Eficiência ambiental estimada na metafronteira; GTE = Eficiência ambiental estimada dentro do grupo; TGI = Ineficiência ambiental causada pelo gap tecnológico; GMI = Ineficiência ambiental causada pelo mau gerenciamento; $M T I$ = Ineficiência ambiental total.

Ademais, verificou-se que poucos municípios tiveram sérios problemas de ineficiência tecnológica (somente 7,46\% mostraram ineficiência acima de $25 \%$, coluna TGI, Tabela 4). Especificamente, essa falha decorre da adoção de tecnologias produtivas mais intensivas em poluentes. Por exemplo, municípios com características industriais podem ser comparativamente menos eficientes do que aqueles em que o setor industrial é pouco representativo. Isto é, o desempenho nesse cenário trata-se de uma questão estrutural. Dessa forma, um município que apresenta tanto ineficiência gerencial quanto tecnológica está não somente produzindo com estruturas mais intensivas, como também está gerindo mal suas emissões quando comparado a seus pares (municípios que também produzem com a mesma estrutura). Apesar de não haver muitos municípios com sérios problemas de ineficiência tecnológica, quase $95 \%$ deles apresentaram ambos os tipos de ineficiência. Abre-se espaço, portanto, para o desenvolvimento de ações que visem promover novos padrões tecnológicos no setor industrial, ampliando a infraestrutura de baixo car- 
bono das firmas brasileiras. Essa seria mais uma ação importante para se alcançar as metas da iNDC brasileira.

Feitas essas considerações, é importante compreender a relação entre a eficiência ambiental dos municípios brasileiros e suas características. Para essa análise, inicialmente testou-se a presença de correlação espacial entre os indicadores de eficiência ambiental por meio de uma análise exploratória de dados espaciais (AEDE). Utilizando a matriz rainha de pesos espaciais, o coeficiente I de Moran calculado foi de aproximadamente 0,20, levando à conclusão de que os escores de eficiência estão espacialmente correlacionados. $O$ sinal positivo do parâmetro indica a existência de clusters Alto-Alto (agrupamento de municípios mais eficientes) e Baixo-Baixo (agrupamento de municípios menos eficientes). Para melhor visualizá-los, apresenta-se a Figura 2.

Figura 2 Clusters para os indicadores de eficiência ambiental dos municípios brasileiros
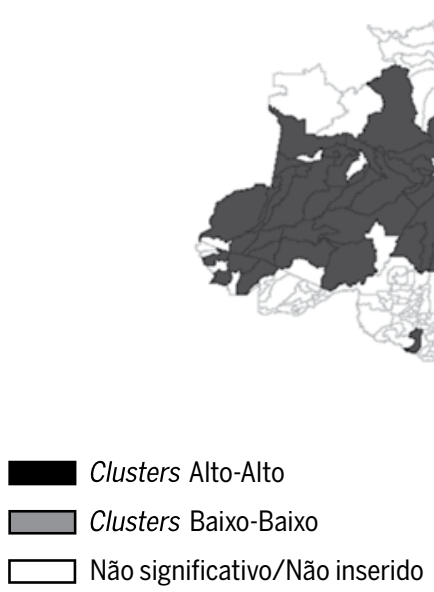

Fonte: Resultado da pesquisa.

A Figura 2 demonstra importante aspecto no que diz respeito às emissões de GEE do país. Embora não haja padrão bem definido de agrupamentos do tipo Alto-Alto, parte expressiva dos agrupamentos Baixo-Baixo encontra-se no Centro-Oeste. É possível que esse resultado seja decorrente 
da relevante atividade pecuária da região, que concentra 34\% do rebanho nacional (IPEA, 2016). Conforme salientam Bustamante et al. (2012), a produção bovina caracteriza-se pela frequente expansão da fronteira agrícola (que aumenta as emissões de GEE, devido ao desmatamento) e por altas emissões de metano, outra fonte expressiva das emissões do Brasil. Uma maneira custo-efetiva de contornar esse resultado negativo, em conformidade com a iNDC, seria investir em políticas de intensificação da pecuária brasileira, caminhando em direção a sistemas mais produtivos e eficientes (COHN et al., 2014). Silva, Ruviaro e Ferreira Filho (2017) reforçam essa ideia ao afirmarem que esses sistemas poderiam reduzir emissões, sobretudo no Centro-Oeste e Norte.

Após a confirmação da existência de correlação espacial, assumiu-se que o desempenho ambiental dos municípios brasileiros depende da especialização produtiva e da capacidade de inovação da região na qual se inserem. Por esse motivo, estimou-se o modelo SAR utilizando o indicador de eficiência ambiental intragrupo, obtido por bootstrap (EFC), e as variáveis que representam as características socioeconômicas municipais abordadas neste estudo.

Foram utilizados os testes de homocedasticidade de White, Breusch-Pagan e Koenker-Bassett, que rejeitaram a hipótese de variância constante. Por isso, o modelo espacial foi estimado considerando a matriz de erros robustos de White. Foi calculado ainda o Fator de Inflacionamento da Variância (FIV) com o intuito de analisar possíveis problemas de multicolinearidade, os quais não foram identificados (FIV $=3,89$ ). Os resultados desse modelo são apresentados na Tabela 5 .

Como esperado, o coeficiente espacial foi positivo e significativo, indicando que um município (in)eficiente tende a se agrupar regionalmente a pares com (pior) melhor performance ambiental (Tabela 5). Esse resultado pode estar associado a diversos fatores, como concentração de atividades produtivas similares, agrupamentos de localidades com o mesmo perfil ambiental, efeito transbordamento de tecnologias ambientais etc. Por exemplo, como já foi falado, os municípios da região Centro-Oeste podem ser ineficientes em razão de sua atividade produtiva. Dada a tendência de concentração produtiva em âmbito regional, é possível que parte desses agrupamentos esteja relacionada a esse aspecto. Esse também pode ser o caso de regiões metropolitanas, que se mostraram eficientes por não haver melhor padrão para serem comparadas, isto é, uma outra metrópole com melhor técnica produtiva (menos intensiva). 
Tabela 5 Resultados do modelo da eficiência ambiental dos municípios brasileiros (EFC)

\begin{tabular}{|c|c|}
\hline Variáveis & SAR \\
\hline \multicolumn{2}{|l|}{ Dependência espacial } \\
\hline Efeito Spillover & $\begin{array}{r}0,3185^{* * *} \\
(0,0160)\end{array}$ \\
\hline \multicolumn{2}{|l|}{ Características socioeconômicas } \\
\hline Índice de Gini & $\begin{array}{r}-0,3943 * * * \\
(0,0543)\end{array}$ \\
\hline Percentual de pessoas pobres & $\begin{array}{r}0,0043^{* * *} \\
(0,0004)\end{array}$ \\
\hline Percentual de pessoas empregadas com ensino superior & $\begin{array}{r}-0,0032^{* * *} \\
(0,0009)\end{array}$ \\
\hline Percentual de domicílios com coleta de lixo & $\begin{array}{r}0,0001 \\
(0,0002)\end{array}$ \\
\hline Renda média dos ocupados & $\begin{array}{r}0,0002^{* * *} \\
(0,0001)\end{array}$ \\
\hline Percentual dos ocupados na indústria & $\begin{array}{r}0,0018^{* * *} \\
(0,0003)\end{array}$ \\
\hline Percentual dos ocupados na agropecuária & $\begin{array}{r}0,0009 * * * \\
(0,0002)\end{array}$ \\
\hline Percentual dos ocupados na extração mineral & $\begin{array}{r}0,0050^{* * *} \\
(0,0012)\end{array}$ \\
\hline IDH-M & $\begin{array}{r}0,0024^{* * *} \\
(0,0004)\end{array}$ \\
\hline \multicolumn{2}{|l|}{ Ações ambientais } \\
\hline Inciativas de consumo sustentável & $\begin{array}{r}0,0081 \\
(0,0052)\end{array}$ \\
\hline Redução do consumo de sacolas plásticas & $\begin{array}{r}-0,0047 \\
(0,0062)\end{array}$ \\
\hline Redução do consumo de água/energia & $\begin{array}{r}0,0017 \\
(0,0061)\end{array}$ \\
\hline Critérios ambientais para licitação & $\begin{array}{r}0,0009 \\
(0,0076)\end{array}$ \\
\hline
\end{tabular}

(continua) 
Tabela 5 (continuação)

\begin{tabular}{lr}
\hline Variáveis & SAR \\
\hline Dummies regionais & \\
\hline Nordeste & 0,0074 \\
\hline Norte & $(0,0075)$ \\
\hline Centro-Oeste & $0,0210^{* *}$ \\
& $(0,0091)$ \\
\hline Sul & $-0,0688^{* * *}$ \\
\hline Constante & $(0,0078)$ \\
\hline Pseudo $R^{2}$ & $0,0110^{* *}$ \\
\hline
\end{tabular}

Fonte: Fonte: Resultados da pesquisa.

Notas: $\left({ }^{* *}\right),\left({ }^{* *}\right)$ e $\left({ }^{*}\right)$ indicam significância a $1 \%, 5 \%$ e $10 \%$, respectivamente; os valores entre parênteses referem-se aos erros-padrão.

Um corolário importante da confirmação da existência de transbordamentos de tecnologias ambientais (Tabela 5) é a necessidade de fortalecimento regional das estratégias da iNDC brasileira. Por exemplo, para atender à necessidade de aumentar a participação de energias renováveis na matriz energética, determinado município poderia incentivar o investimento em micro e minigeração distribuída de energia solar por meio de painéis fotovoltaicos. A partir disso, é possível que ocorra a difusão da tecnologia, ou seja, a criação de práticas sustentáveis locais possivelmente gerará externalidades positivas regionais.

Os resultados da Tabela 5 também mostram que pobreza, renda e IDH apresentaram relação positiva com a eficiência ambiental dos municípios. Sobre a pobreza, conforme argumentado anteriormente, sua incidência pode sugerir concentração de atividades com menor efeito relativo sobre as emissões, tal como a agricultura familiar ou de autoconsumo. Dessa forma, municípios com maior percentual de pobres tendem a ser mais eficientes ambientalmente em função do tipo de atividade que desempenham. De fato, esse parece ser o efeito que prevalece no caso brasileiro.

Do mesmo modo, municípios com renda e IDH mais elevados (mais desenvolvidos) também podem se concentrar em atividades com menor 
impacto ambiental, como os setores de serviços, tecnologia, informação etc. Nesse contexto, haveria relação positiva entre essas variáveis e a eficiência ambiental, como o presente estudo indica. Ademais, regiões mais desenvolvidas podem apresentar maior disposição a pagar pela preservação (ou maior resistência a atividades intensivas em emissões).

Em sentido contrário, desigualdade e educação mostraram relação negativa com a eficiência ambiental (Tabela 5). Sobre a desigualdade, o argumento é que a concentração de renda intensifica o uso dos recursos naturais e as emissões, visto que a sociedade pode ter baixa disposição a pagar pela preservação. Outro ponto que pode ser levantado é a influência de minorias no desenvolvimento de leis ambientais municipais. Esses argumentos estão em linha com a hipótese de que sociedades mais ricas têm maior potencial de adaptação a efeitos ambientais adversos e, portanto, estão menos dispostas a investir em mitigação no curto prazo (Aklin et al., 2013).

No caso da educação, prevaleceu o efeito "produtividade": relação negativa entre grau educacional e eficiência ambiental. Concretamente, no grupo das metrópoles, os municípios com maior percentual de ocupados com ensino superior foram os menos eficientes. Esse fato se estende aos municípios de médio e pequeno portes. Deve-se notar que esse resultado não contradiz, necessariamente, os argumentos da CAK. Retomando suas hipóteses, alega-se que a educação é uma das variáveis-chave para diminuir o nível de emissões. No entanto, seu efeito somente será percebido em uma etapa do desenvolvimento na qual a sociedade terá alta educação e renda. Ou seja, para os países em desenvolvimento, apenas no médio e longo prazos. Entretanto, em razão da restrição de dados, o presente estudo não permite análises nesses horizontes temporais.

Outro fator que merece ser destacado refere-se ao grau de especialização dos municípios, medido pelo percentual dos ocupados nos setores produtivos. Verificou-se relação positiva entre especialização produtiva e desempenho ambiental. Ocorre que a especialização produtiva pode melhorar a forma na qual os municípios gerenciam recursos naturais e emissões. Pode-se considerar, por exemplo, o caso de alguns municípios extrativistas de médio porte. Apesar de possuírem maior ineficiência tecnológica (pois o setor é mais intensivo em emissões), sua eficiência gerencial foi maior em relação aos demais. Isso leva a crer que a especialização produtiva pode expandir a produção e minimizar os efeitos ambientais em proporção. A magnitude do parâmetro indica a intensidade do "efeito 
especialização" do setor sobre a eficiência ambiental. Pode-se observar que municípios com especialização industrial possuem melhores indicadores e, em seguida, os extrativistas e os agropecuários.

Por fim, em relação às ações ambientais, notou-se que nenhuma variável foi estatisticamente significativa, reflexo, sobretudo, do baixo enforcement da legislação ambiental do país, apesar dos esforços que têm sido feitos no sentido de estabelecer diretrizes para a redução das emissões (Brasil, 2015). Observa-se que a maioria dos municípios (58\%) não desenvolveu ações ambientais para incentivar o consumo sustentável no ano da pesquisa. A inexistência de mecanismos econômicos de incentivo em nível local, como critério ambiental para concorrer a licitações, pode explicar o presente resultado, já que apenas alguns municípios (8\%) mostraram propostas como essa. Em geral, regiões com piores indicadores de eficiência, como o Centro-Oeste, apresentam um número relativamente pequeno de propostas para melhorar o quadro ambiental.

\section{Conclusões}

Considerando a importância do estudo do desempenho ambiental dos países no que se refere às emissões de GEE, o presente artigo obteve evidências de que a eficiência ambiental do Brasil tem sido baixa. Os problemas de controle das emissões foram preponderantes em quase todos os municípios do país, indicando que as cidades brasileiras não estão lidando adequadamente com a questão. Falta de normas rígidas, baixa fiscalização, inexistência e, ou, ineficácia de políticas ambientais etc. podem ser possíveis explicações para esse quadro.

Evidenciou-se que a eficiência ambiental não está somente relacionada com a forma de produzir, mas também com certas características municipais. Existe a tendência, por exemplo, de que municípios de renda e desenvolvimento mais elevados sejam mais eficientes, principalmente por se concentrarem em setores com menor grau de emissões, como serviços e tecnologia. Ademais, a disposição para pagar pela preservação pode ser maior nessas regiões. Ao mesmo tempo, localidades muito pobres também podem ter níveis elevados de eficiência. Nesse caso, a incidência da pobreza poderia indicar maior proporção de atividades menos intensivas, como agricultura para autoconsumo. Também merece ser destacado o fato 
de que regiões com maior percentual de pessoas com ensino superior foram menos eficientes. Constatou-se que no país prevaleceu o efeito "produtividade", o qual ocorre quando a escolaridade se associa mais com a elevação do produto do que com a "consciência ambiental".

Pode-se concluir ainda que há significativas desigualdades regionais no que diz respeito à (in)eficiência ambiental. A princípio, esse fato poderia representar dificuldade à implementação de uma política nacional de redução de emissões, como aquela proposta pela iNDC do Brasil. Não obstante, a observação dessa particularidade deveria guiar uma reformulação da política climática brasileira no sentido de dar-lhe caráter local e descentralizado, em vez de apenas considerar especificidades setoriais, como é feito atualmente. Algumas políticas, tais como aquelas voltadas ao cumprimento do Código Florestal (redução do desmatamento, aumento da restauração florestal etc.), ao fortalecimento do Plano de Agricultura de Baixa Emissão de Carbono e à expansão do uso de fontes renováveis na matriz energética (eólica, biomassa e solar) têm caráter essencialmente regional. Assim, se fossem descentralizadas, considerando as especificidades de cada localidade, poderiam ser potencializadas pelo efeito spillover identificado neste estudo.

Diante do exposto, pode-se concluir que um dos grandes desafios que o Brasil enfrentará nas próximas décadas será o de preparar os municípios, sobretudo os de menor porte, para se desenvolver economicamente, respeitando os limites do meio ambiente. As políticas ambientais em âmbito regional terão papel importante, pois os municípios tendem a aprender com as boas práticas, isto é, a criação de ações sustentáveis pode produzir externalidades positivas regionalmente, contribuindo para a difusão de um modelo econômico menos intensivo em emissões.

Por fim, este estudo não teve a pretensão de dar uma resposta definitiva à questão da (in)eficiência ambiental em termos de emissões de GEE no Brasil. Ainda existem limitações, sobretudo de dados, que precisam ser superadas pelos órgãos oficiais para que estudos futuros avancem em relação à presente pesquisa. Não obstante, os resultados aqui apresentados, inéditos na literatura nacional, demonstram que há necessidade de planejamento para que as metas de crescimento/desenvolvimento econômico não ultrapassem as barreiras ambientais e não comprometam os compromissos nacionais de redução de emissões. Nesse sentido, a política climática brasileira deveria considerar as questões aqui debatidas. 


\section{Referências}

AFONSO, A.; SCHUKNECHT, L.; TANZI, V. Public sector effiiency: Evidence for New EU Members States and Emerging Markets. European Central Bank Working Paper, n. 581, 2006.

AKLIN, M. et al. Understanding environmental policy preferences: New evidence from Brazil. Ecological Economics, 94, n. 1, p. 28-36, 2013.

ANSELIN, L. Spatial econometrics: Methods and models. [S.I.]: Kluwer Academic Publishers, 1988.

ASHWORTH, J.; GEYS, B.; HEYNDELS, B. Determinants of tax innovation: The case of environmental taxes in Flemish municipalities. European Journal of Political Economy, p. 223$247,2006$.

BANKER, R. D.; CHARNES, A.; COOPER, W. W. Some models for estimating technical and scale. Management Science, 30, n. 9, p. 1078-1092, 1984.

BAUMONT, C.; ERTUR, C.; LE GALO, J. Spatial analysis of employment and population density: The case of the agglomeration of Dijon (1999). Geographical Analysis, 36, n. 2, p. 146-176, 2004.

BEISE, M.; RENNINGS, K. Lead markets and regulation: A framework for analyzing the international diffusion of environmental innovations. Ecological Economics, n. 52, p. 5-17, 2005.

BOYCE, J. K. Inequality as a cause of environmental degradation. Ecological Economics, 11, 1994.

BRASIL. Estimativas anuais de emissões de gases de efeito estufa no Brasil. MINISTÉRIO DA CIÊNCIA, TECNOLOGIA E INOVAÇÃO, Brasília, p. 76, 2013. Disponivel em: <http:// gvces.com.br/arquivos/177/EstimativasClima.pdf>. Acesso em: 25 jul. 2014.

BRASIL. Intended Nationally Determined Contribution Towards Achieving the Objective of the United Nations Framework Convention on Climate Change - iNDC. Brasília. 2015.

BUSTAMANTE, M. M. C. et al. Estimating greenhouse gas emissions from cattle raising in Brazil. Climatic Change, 115, p. 559-577, 2012.

CHIU, C. et al. Decomposition of the environmental inefficiency of the meta-frontier with undesirable output. Energy Economics, p. 1392-1399, 2012.

CHUNG, Y. H.; FÄRE, R.; GROSSKOPF, S. Productivity and Undesirable Outputs: A Directional Distance Function Approach. Journal of Environmental Management, p. 229-240, 1997.

$\mathrm{COHN}, \mathrm{A}$. S. et al. Cattle ranching intensification in Brazil can reduce global greenhouse gas emissions by sparing land from deforestation. PNAS, 111, n. 20, p. 7236-7241, 2014.

DAREN, C. Education and Economic Growth: Is There a Link? Munich Personal RePEc Archive, n. 18.176, 2007.

DENATRAN. Departamento Nacional de Trânsito, 2015. Disponivel em: <http://www.denatran.gov.br/>. Acesso em: 25 jan. 2015.

DER ENG, P. Capital Formation and Capital Stock in Indonesia, 1950-2007. Working Papers in Trade and Development, 2008.

FÄRE, R.; GROSSKOPF, S. Modeling undesirable factors in efficiency evaluation: Comment. European Journal of Operational Research, p. 242-245, 2004. 
FÄRE, R.; GROSSKOPF, S.; LOVELL, C. A. K. Multilateral productivity comparisons when some outputs are undesirable: a nonparametric approach. The Review of Economics and Statistics, p. 90-98, 1989.

FÄRE, R.; GROSSKOPF, S.; NOH, D. Characteristics of a Polluting Technology: Theory and Practice. Journal of Econometrics, p. 469-492, 2005..

FÄRE, R.; GROSSKOPF, S.; TYTECA, D. An activity analysis model of the environmental performance of firms application to fossil-fuel-fired electric utilities. Ecological Economics, n. 18, p. 161-175, 1996.

FÄRE, R.; PRIMONT, D. Multi-output Production and Duality: Theory and Applications. Kluwer Academic Publishers, 1995.

GASSEBNER, M.; LAMLA, M.; STURM, J. Economic, demographic and political determinants of pollution reassessed: a sensitivity analysis. CESifo working paper, 1699, 2006.

GÜTSCHOW, J. et al. The PRIMAP-hist national historical emissions time series. Earth System Science Data, 8, p. 571-603, 2016.

HALKOS, G. E.; TZEREMES, N. G. A conditional directional distance function approach for measuring regional environmental efficiency: Evidence from UK regions. European Journal of Operational Research, n. 227, p. 182-189, 2013a.

HONMA, S. Environmental and economic efficiencies in the Asia-Pacific region. Munich Personal RePEc Archive, n. 43. p. 361, 2012.

HUBER, J. Pioneer countries and the global diffusion of environmental innovations: Theses from the viewpoint of ecological modernisation theory. Global Environmental Change, n. 18 , p. 360-367, 2008.

IBGE. Instituto Brasileiro de Geografia e Estatística, 2016. Acesso em: Dezembro 2016.

IPCC. INTERGOVERNMENTAL PANEL ON CLIMATE CHANGE, 2014. Disponível em: $<$ http://www.ipcc.ch/>. Acesso em: Janeiro 2014.

IPEA. Instituto de Pesquisa Econômica Aplicada, 2016. Disponivel em: <http://www.ipeadata.gov.br/>. Acesso em: 25 jan. 2016.

IYER, K.; RAMBALDI, A.; TANG, K. K. Globalisation and the Technology Gap: Regional and Time Evidence, Leading Economic and Managerial Issues Involving Globalisation. Nova Science New York, p. 213-227, 2006.

KORTELAINEN, M. Dynamic environmental performance analysis: A Malmquist index approach. Ecological Economics, p. 701-715. 2008.

KUOSMANEN, T.; KORTELAINEN, M. Measuring Eco-efficiency of Production with Data Envelopment Analysis. Journal of Industrial Ecology, 9, n. 4, 2005.

LESAGE. The Theory and Practice of Spatial Econometrics. [S.1.]: [s.n.], 1999. Disponivel em: <http://raptor1.bizlab.mtsu.edu/s-drive/TEFF/sbook.pdf>. Acesso em: 25 jan. 2016.

LI, M.; WANG, Q. International environmental efficiency differences and their determinants. Energy, n. 78, p. 411-420, 2014.

MARTIN, J. L.; MARIS, V.; SIMBERLOFF, D. S. The need to respect nature and its limits challenges society and conservation science. PNAS, 113, n. 22, p. 6105-6112, 2016.

MEI, G.; GAN, J.; ZHANG, N. Metafrontier Environmental Efficiency for China's Regions: 
A Slack-Based Efficiency Measure. Sustainability, n. 7,p. 4004-4021, 2015.

O'DONNELL, C. J.; RAO, D. S. P.; BATTESE, G. E. Metafrontier frameworks for the study of firm-level efficiencies and technology ratios. Empirical Economics, 34, p. 231-255, 2008.

$\mathrm{OH}, \mathrm{D}$. H.; LEE, J. D. A metafrontier approach for measuring Malmquist productivity index. Empirical Economics, 38, n. 1, p. 47-64, 2010.

PBDA. Portal Brasileiro de Dados Abertos, 2016. Disponivel em: <http://dados.gov.br/>. Acesso em: 25 jan. 2016.

PNUD. Programa das Nações Unidas, 2016. Disponivel em: <http://www.pnud.org.br/>. Acesso em: 25 jan. 2016.

ROCHA, F. et al. Mais recursos ou mais eficiência? Uma análise de oferta e de demanda por serviços de saúde no Brasil. Textos para Discussão. Tesouro Nacional, n. 10, 2012.

SILVA, J. G.; RUVIARO, C. V.; FERREIRA FILHO, J. B. Livestock intensification as a climate policy: Lessons from the Brazilian case. Landy Use Policy, 62, p. 232-245, 2017.

SIMAR, L.; WILSON, P. W. Sensitivity Analysis of Efficiency Scores: How to Bootstrap in Nonparametric Frontier Models. Management Science, 44, n. 1, 1998.

SONG, X.; HAO, Y.; ZHU, X. Analysis of the Environmental Efficiency of the Chinese Transportation Sector Using an Undesirable Output Slacks-Based Measure Data Envelopment Analysis Model. Sustainability, n. 7, p. 9187-9206, 2015.

SPEIGHT, A.; THOMPSON, P. Is Investment Time Irreversible? Some Empirical Evidence for Disaggregated UK Manufacturing Data. Applied Economics, 38, n. 19, p. 2265-2275, 2006.

STERN, D. I.; COMMON, M. S.; BARBIER, E. B. Economic Growth and Environmental Degradation: The Environmental Kuznets Curve and Sustainable Development. World Development, p. 1151-1160, 1996.

WANG, Q.; ZHANG, H.; ZHANG, W. A Malmquist CO2 emission performance index based on a metafrontier approach. Mathematical and Computer Modelling, p. 1068-1073, 2013.

WORLD BANK. World Bank Group, 2016. Disponivel em: <http://www.worldbank.org/>. Acesso em: 25 jan. 2016.

YUSUF, A. A. Poverty and Environmental Degradation: Searching for Theoretical Linkages. Working Paper in Economics and Development Studies, n. 200403, 2004.

ZHANG, J.; XING, Z.; WANG, J. Analysis of CO2 emission performance and abatement potential for municipal industrial sectors in Jiangsu, China. Sustainability, 8, n. 7, p. 697711, 2016.

ZHANG, N.; CHOI, Y. Total-factor carbon emission performance of fossil fuel power plants in China: A metafrontier non-radial Malmquist index analysis. Energy Economics, p. 549$559,2013$.

ZHOU, P.; ANG, B. W. Decomposition of aggregate CO2 emissions: A production-theoretical approach. Energy Economics, p. 1054-1067, 2008.

ZHOU, P.; HAN, J. Y.; ANG, B. W. Total factor carbon emission performance: A Malmquist index analysis. Energy Economics, p. 194-201, 2010. 


\section{Sobre os autores}

Thiago Costa Soares-thiago.costa@ufff.edu.br

Universidade Federal de Juiz de Fora, campus Governador Valadares, Governador Valadares, Minas Gerais, Brasil. ORCID: https://orcid.org/0000-0002-0117-3785.

Dênis Antônio da Cunha - denis.cunha@ufv.br

Universidade Federal de Viçosa, Viçosa, Minas Gerais, Brasil.

ORCID: https://orcid.org/0000-0003-4838-3795.

O presente estudo foi realizado com apoio da Coordenação de Aperfeiçoamento de Pessoal de Nível Superior - Brasil (Capes) - Código de financiamento 001. O autor Dênis Antônio da Cunha agradece ao Conselho Nacional de Desenvolvimento Científico e Tecnológico (CNPQ) pela concessão de bolsa de produtividade em pesquisa (processo no. 305807/2018-8) Os autores agradecem aos revisores anônimos por seus comentários, úteis e construtivos, que ajudaram a melhorar substancialmente a qualidade da pesquisa. Quaisquer erros remanescentes são de nossa exclusiva responsabilidade.

\section{Sobre 0 artigo}

Recebido em 21 de novembo de 2016. Aprovado em 25 de junho de 2017. 


\section{APÊNDICE}

Figura A1 Mapa das emissões de GEE nos municípios brasileiros em 2010

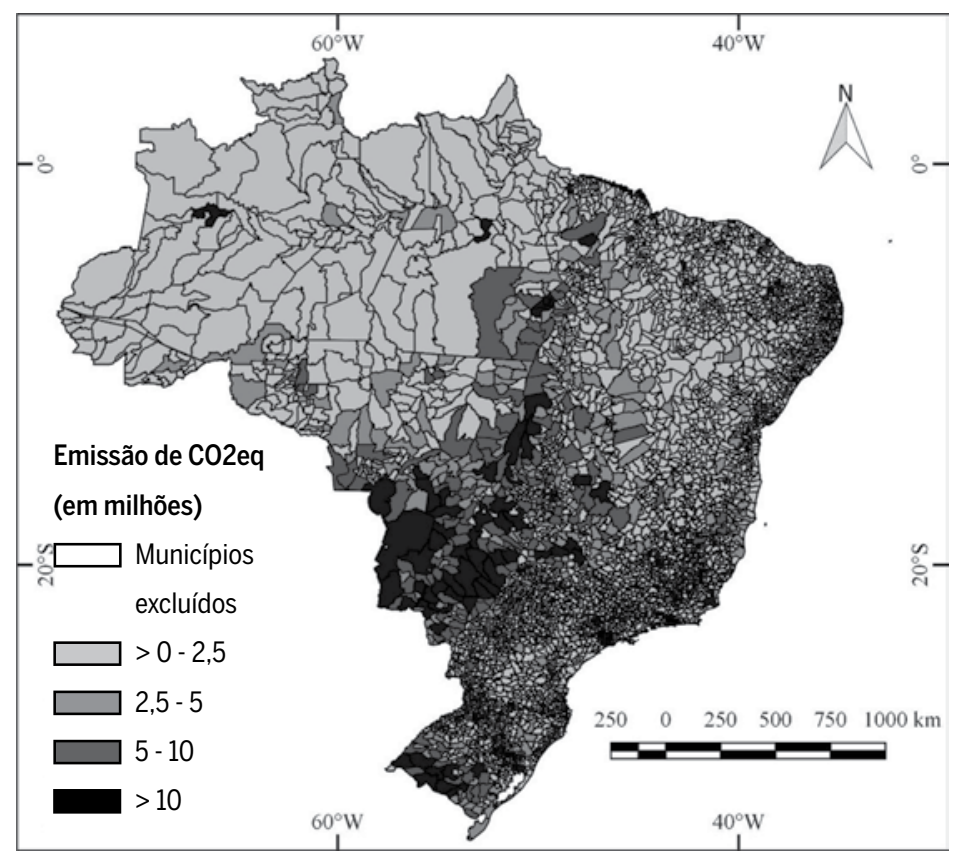

Fonte: Elaborado pelos autores com base em EDGAR, FT V4.2 2010. 
Tabela A1 Descrição dos grupos

\begin{tabular}{|c|c|c|c|}
\hline \multicolumn{4}{|c|}{ Metrópoles (17 observações) } \\
\hline Grupo & Obs. & $(\%)$ & Descrição \\
\hline \multicolumn{2}{|l|}{ MT1 } & 23,5 & Escolaridade e desenvolvimento médios \\
\hline \multicolumn{2}{|l|}{ MT2 } & 23,5 & Industriais e desenvolvimento alto \\
\hline \multicolumn{2}{|l|}{ MT3 } & 23,5 & Industriais e desenvolvimento médio \\
\hline \multicolumn{2}{|l|}{ MT4 } & 29,5 & Escolaridade e desenvolvimento altos \\
\hline \multicolumn{4}{|c|}{ Grandes (226 observações) } \\
\hline Grupo & Obs. & $(\%)$ & Descrição \\
\hline \multicolumn{2}{|l|}{ GR1 } & 33,6 & Comerciais e desenvolvimento médio \\
\hline \multicolumn{2}{|l|}{ GR2 } & 28,8 & Industriais e desenvolvimento médio \\
\hline \multicolumn{2}{|l|}{ GR3 } & 37,6 & Agrícolas e desenvolvimento baixo \\
\hline \multicolumn{4}{|c|}{ Médios (309 observações) } \\
\hline Grupo & Obs. & $(\%)$ & Descrição \\
\hline MD1 & 116 & 37,5 & Comerciais e desenvolvimento baixo \\
\hline MD2 & 66 & 21,4 & Agrícolas e desenvolvimento baixo \\
\hline MD3 & 119 & 38,5 & Industriais e desenvolvimento médio \\
\hline MD4 & 8 & 2,6 & Extrativistas e desenvolvimento médio \\
\hline \multicolumn{4}{|c|}{ Pequenos II (991) observações } \\
\hline Grupo & Obs. & $(\%)$ & Descrição \\
\hline PQII-1 & 294 & 29,7 & Agrícolas e desenvolvimento baixo \\
\hline PQII-2 & 40 & 4,04 & Extrativistas e desenvolvimento médio \\
\hline PQII-3 & 321 & 32,4 & Junção e desenvolvimento baixo \\
\hline PQII-4 & 336 & 33,7 & Industriais e desenvolvimento médio \\
\hline \multicolumn{4}{|c|}{ Pequenos I (3244) observações } \\
\hline Grupo & Obs. & $(\%)$ & Descrição \\
\hline PQI-1 & 964 & 29,7 & Junção e desenvolvimento médio \\
\hline PQI-2 & 966 & 29,7 & Agrícolas e desenvolvimento baixo \\
\hline PQI-3 & 884 & 27,3 & Agrícolas e desenvolvimento baixo II \\
\hline $\mathrm{PQI}-4$ & 430 & 13,3 & Industriais e desenvolvimento médio \\
\hline
\end{tabular}

